\title{
Erratum to: Hypsometric demography of Kosovo: the distribution of Kosovo population by altitude
}

Rizah Murseli and Hazer Dana

\section{Erratum to: City Territ Archit (2016) 3:24 DOI 10.1186/s40410-016-0047-8}

Upon publication of this article (Murseli and Dana 2016), the following errors were brought to our attention:

The second paragraph of the 'Methods' section stating: "The data on agricultural land are taken from dataset of agricultural land suitability divided into eight classes according to Kosovo national classification" is corrected to read: "The data on agricultural land are taken from dataset of agricultural land suitability divided into eight classes according to present Kosovo national classification system (Ministry of Agriculture, Forestry and Rural Development)."

The following reference has been omitted from the 'References' list: Pushka A. 'Quantitative Methods in Geography'. University of Prishtina, Prishtinë 1985.

The above two corrections have been updated in the original article.
Furthermore, the authors would also like to correct the name of Mr. Idriz Shala which was incorrectly included as Mr. Idriz Gashi in the 'Acknowledgements' section of the original article (Murseli and Dana 2016).

The online version of the original article can be found under doi:10.1186/s40410-016-0047-8.

Received: 12 December 2016 Accepted: 12 December 2016 Published online: 27 January 2017

\section{Reference}

Murseli R, Dana H (2016) Hypsometric demography of Kosovo: the distribution of Kosovo population by altitude. City Territ Archit 3:24. doi:10.1186/ s40410-016-0047-8 